\title{
BMJ Open The impact of demand management strategies on parents' decision-making for out-of-hours primary care: findings from a survey in The Netherlands
}

\author{
Marie-Jeanne Giesen, ${ }^{1,2}$ Ellen Keizer, ${ }^{1}$ Julia van de Pol, ${ }^{1}$ Joris Knoben, ${ }^{3}$ \\ Michel Wensing, ${ }^{1,4}$ Paul Giesen ${ }^{1}$
}

To cite: Giesen M-J, Keizer E, van de Pol J, et al. The impact of demand management strategies on parents' decisionmaking for out-of-hours primary care: findings from a survey in The Netherlands. BMJ Open 2017;7:e014605. doi:10.1136/ bmjopen-2016-014605

- Prepublication history and additional material are available. To view please visit the journal (http://dx.doi.org/ 10.1136/ bmjopen-2016-014605).

Received 6 0ctober 2016 Revised 22 March 2017 Accepted 23 March 2017

\section{(1) CrossMark}

${ }^{1}$ Radboud Institute for Health Sciences, Scientific Center for Quality of Healthcare, Radboud University Medical Center, Nijmegen, the Netherlands ${ }^{2}$ TiasNimbas Business School, Tilburg University, Tilburg, the Netherlands

${ }^{3}$ Institute for Management Research, Radboud University, Nijmegen, the Netherlands ${ }^{4}$ Department of General Practice and Health Services Research, University Hospital Heidelberg, Heidelberg, Germany

Correspondence to Ellen Keizer; Ellen.Keizer@ radboudumc.nl

\section{ABSTRACT}

Objective To explore the potential impact of demand management strategies on patient decision-making in medically non-urgent and urgent scenarios during out-ofhours for children between the ages of 0 and 4 years. Design and methods We conducted a cross-sectional survey with paper-based case scenarios. A survey was sent to all 797 parents of children aged between 0 and 4 years from four Dutch general practitioner (GP) practices. Four demand management strategies (copayment, online advice, overview medical cost and GP appointment next morning) were incorporated in two medically non-urgent and two urgent case scenarios. Combining the case scenarios with the demand management strategies resulted in 16 cases (four scenarios each with four demand management strategies). Each parent randomly received a questionnaire with three different case scenarios with three different demand strategies and a baseline case scenario without a demand management strategy.

Results The response rate was $47.4 \%$. The strategy online advice led to more medically appropriate decisionmaking for both non-urgent case scenarios (OR 0.26; $95 \% \mathrm{Cl} 0.11$ to 0.58 ) and urgent case scenarios (OR 0.16; $95 \% \mathrm{Cl} 0.08$ to 0.32 ). Overview of medical cost (OR 0.59; $95 \% \mathrm{Cl} 0.38$ to 0.92 ) and a GP appointment planned the next morning (OR $0.57 ; 95 \% \mathrm{Cl} 0.34$ to 0.97 ) had some influence on patient decisions for urgent cases, but not for non-urgent cases. Copayment had no influence on patient decisions.

Conclusion Online advice has the highest potential to reduce medically unnecessary use. Furthermore it enhanced safety of parents' decisions on seeking help for their young children during out-of-hours primary care. Valid online information on health symptoms for patients should be promoted.

\section{INTRODUCTION}

In the Netherlands out-of-hours primary care is provided by general practitioner cooperatives (GPCs) and is intended for urgent complaints that cannot wait until the next day. ${ }^{1}$ However, half of the requests are medically non-urgent, ${ }^{2}$ and many of these requests can wait until office hours or can be managed

\section{Strengths and limitations of this study}

The study sample was representative of the Dutch population.

- Both non-urgent and urgent case scenarios were used to test the demand management strategies.

- Hypothetical situations were used to test the demand management strategies.

- Only one amount of the copayment and its effectiveness was tested.

with self-care. Inappropriate, non-urgent contacts affect the motivation of triage nurses and general practitioners (GPs), and result in a higher workload which could negatively affect the quality of out-of-hours primary care. ${ }^{34}$ Also, the cost for a consultation at the GPC is higher (about $€ 100$ ) than for a consultation during office hours $(€ 40)$. These costs are not directly paid by patients. Patients pay a monthly overall premium to their health insurance providers. Primary care is exempted from copayment by patients, contrary to most other types of healthcare. GPs are looking for measures to reduce the number of patients with non-urgent complaints, such as copayment for patients, stricter triage and a larger role for the telephone consultation doctor. ${ }^{4}$

To support patient decision-making on healthcare use during out-of-hours and regulate demand for primary healthcare, a number of strategies could be effective. Demand management strategies are widely used in the service industry to enable effective and efficient use of capacity. When applied in healthcare, these strategies have the potential to influence the patient's perceived demand through education, financial incentives or organisational rescheduling. ${ }^{4-6}$ Accordingly they can reduce demand that is unlikely to improve health ${ }^{56}$ while having minimal effect on genuine, urgent cases so as not to jeopardise appropriate care. 
Demand management strategies are patient-targeted methods, which approach the aim to prevent overcrowding and enhance the efficiency of the healthcare system, while maintaining high standards of quality and accessibility. The main demand management strategy currently used at GPCs is telephone triage. ${ }^{6}$ However, patients continue to visit the GPC directly, or get 'through' the triage system, with non-urgent complaints. GPs see these patients with non-urgent complaints as one of the most negative aspects of the GPC system. ${ }^{3}$

Giesen $e t a l^{7}$ found that, of all patient populations, parents with children between the ages of 0 and 4 years most often contact the GPC with non-urgent conditions. In many of these cases, it would be more appropriate to visit the GP during daytime or apply self-care from a medical and societal perspective. ${ }^{7}$ Previous research also showed that childhood fever does account for a large workload at GPCs. ${ }^{8}$ Considering the potential effects of demand management strategies in healthcare, it would be valuable to explore which demand management strategies could be effective to reduce non-urgent demand at GPCs for this specific population. The objective of our study was to explore the potential impact of demand management strategies on patient decision-making in both medically non-urgent and urgent scenarios during out-of-hours for children between the ages of 0 and 4 years.

\section{METHODS}

\section{Design, setting and population}

We conducted a cross-sectional survey with paper-based case scenarios. Four GP practices from both rural and urban areas in the east of the Netherlands participated. A survey was sent to all families in their patient population with children aged between 0 and 4 years $(n=797)$. A reminder was sent 2 weeks after the first invitation. The study was conducted between 2013 and 2015.

\section{Questionnaire}

A questionnaire was developed over several rounds by researchers and medical professionals. The questionnaire included questions about the background of the patient (gender, age, education level, income, number of children, age of oldest and youngest child), followed by questions related to the paper-based case scenarios. Two pilot studies were conducted to ensure the validity of the survey and test its user-friendliness. In the first pilot study a convenience sample of individuals participated, and in the second pilot study 16 patients from one GP practice participated.

\section{Strategies}

In combining the insights on demand for out-of-hours primary care with the findings from previous studies on decision-making and demand management strategies in healthcare, there are several strategies that can potentially be effective to influence the demand for GPCs. ${ }^{3-5} 7$ We identified the following demand management strategies to be tested in our research: copayment, online advice, overview medical cost and direct GP appointment next morning (see online supplementary appendix A).

Copayment can be implemented via a fee that has to be paid directly by the patient. We set the fee for a GPC at $€ 75$ and for the emergency department at $€ 150$. Online advice is based on the principle to support patients in their decision-making. We presented online advice that was given by an application certified by the Dutch Society of General Practitioners (NHG). This strategy does not limit the entry to the GPC like copayment does, and may therefore be considered an interesting alternative to the copayment strategy. Another possible effective demand management strategy is to give patients insight into the cost of medical treatments. This strategy would be a midway option between the somewhat controversial copayment and education on medical conditions via online advice. The fourth demand management strategy tested is to enable patients to make an immediate next-working day appointment with their GP via an online scheduling system. This strategy could give patients the certainty of an appointment during office hours, and might thus reduce the probability they will contact a GPC for a health condition that is non-urgent. This strategy would be particularly relevant to the patient group that sought the services of a GPC but were unable to reach their own GP or make an appointment during office hours. ${ }^{9}$

\section{Case scenarios}

The case scenarios were used in an early study about telephone triage and were presented to an expert panel consisting of three triage nurses and three GPs. ${ }^{10}$ The expert panel determined the 'reference standard' regarding the appropriate type of care. We included two non-urgent and two urgent common cases (see online supplementary appendix B). The non-urgent cases were cases for which contact with the GPC (the same day) was not medically necessary, and the urgent cases were cases for which contact with the GPC (the same day) was medically necessary. Combining the case scenarios selected with the demand management strategies, 16 cases were devised (four scenarios each with four demand management strategies). To test all scenario-demand strategy combinations, four questionnaires were developed. Combining the case scenarios with the demand management strategies resulted in 16 cases (four scenarios each with four demand management strategies). Each parent randomly received a questionnaire with three different case scenarios with three different demand strategies and a baseline case scenario without a demand management strategy. Due to a mistake in one of the cases in the questionnaire, we excluded the answers of 141 respondents regarding that case. The baseline case scenario was included to test how respondents would react in the different case scenarios when no demand management strategy was included.

The effects of demand management strategies on patient decision-making were verified by testing if the choices made by the respondents matched the 
Table 1 Classification of answer categories

\begin{tabular}{llll}
\hline Non-urgent scenario & & & Urgent scenario \\
\hline Answer category & Classification & Answer category & Classification \\
\hline $\begin{array}{llll}\text { I would wait/apply self-care } \\
\text { solutions }\end{array}$ & Medically appropriate demand & $\begin{array}{l}\text { I would wait/apply self-care } \\
\text { solutions }\end{array}$ & Underdemand \\
I would contact my General & & I would contact my General \\
Practitioner during office hours & & Practitioner during office hours & Medically appropriate \\
I would contact the General & Overdemand & I would contact the General & demand \\
Practitioners' Cooperation & & Practitioners' Cooperation & Overdemand \\
I would visit the Emergency & & I would visit the Emergency & Department \\
Department & & I would call 112 (emergency line) &
\end{tabular}

reference standard of the expert panel. To test this, we rearranged the answers into categories. The answers to the non-urgent scenarios were categorised into 'medically appropriate demand' or 'overdemand', while the answers to the urgent scenarios were categorised into 'underdemand', 'medically appropriate demand' and 'overdemand' (table 1).

\section{Statistical analyses}

Descriptive statistics were used to describe the characteristics of the respondents and the percentages of overdemand and underdemand for each strategy. The choices of the parents (with either overdemand or underdemand coded as ' 1 ' and the other choices as ' 0 ') have been tested in two separate logistic regression analyses at the case level. The answers to the baseline case scenarios served as a reference category, meaning that both non-urgent and urgent scenarios presented with demand management strategies have been tested against answers given for the baseline scenarios. We corrected for patient characteristics (gender, age, amount of children, education level and income) and added the variable GP practice to account for clustering of patients within GP practices. Analyses were performed in SPSS V.22.0.

\section{RESULTS}

\section{Characteristics of respondents}

The response rate was $47.3 \% \quad(n=377)$, providing answers to 1367 cases. Of the respondents $42.5 \%$ lived in urban areas, $17 \%$ in suburban areas and $40.6 \%$ in rural areas (table 2). Most of the participants finished tertiary school $(41.6 \%)$ and indicated their income as similar to the average Dutch household income $(34.5 \%) .{ }^{11}$ The average number of children per parent was 2.1. The mean age of the oldest child was 4.8 years and of the youngest child 1.7 years.

\section{Case scenarios}

Regarding the non-urgent scenarios, $41.7 \%$ of the parents made an overdemand choice (table 3 ). For the urgent scenarios, $50.3 \%$ of the respondents made an underdemand choice and $3.9 \%$ an overdemand choice.

\section{Case scenarios with demand management strategies}

Overall, the percentage of parents who made an overdemand choice for the non-urgent case scenarios without a demand management strategy was $41.7 \%$ (table 4 ). By providing the strategy 'online advice', the percentage of overdemand decreased by $30.4 \%$. The strategy 'copayment' was found to reduce the probability of overdemand to $31.7 \%$, realising a decrease of $10.0 \%$ compared with the baseline strategy. We did not find large differences when the strategies 'GP consult planned' and 'overview of medical cost' were used.

An underdemand solution for the urgent case scenarios without a demand strategy ('baseline') was chosen by $50.3 \%$. When using the strategy 'online advice', $16.5 \%$ chose an underdemand solution, a decrease of $33.8 \%$. The strategy 'overview medical cost' reduced the probability of underdemand by $10.9 \%$. With the use of the strategy 'GP consult planned', the probability of an underdemand decision was decreased by $9.7 \%$. The strategy 'copayment' seems to have no influence, as with this strategy $50.0 \%$ still chose an underdemand solution.

\section{Influence of demand management strategies on non-urgent and urgent case scenarios}

Table 5 shows that when the strategy 'online advice' was used for non-urgent cases, parents more frequently made a medically appropriate healthcare choice (OR 0.26; $95 \%$ CI 0.11 to 0.58$)$. The other strategies had no influence on the parents' decisions in non-urgent cases. We also found that parents with more than one child made an appropriate choice more often than parents with just one child (OR $0.64 ; 95 \%$ CI 0.43 to 0.96 ).

For the urgent cases, we found that the application of online advice influences parent decision-making positively, resulting in more medically appropriate choices (OR 0.16 ; $95 \%$ CI 0.08 to 0.32 ). The strategy of showing the medical cost of a visit to the GPC also results in more medically appropriate choice behaviour (OR 0.59; 95\% CI 0.38 to 0.92 ), as did the strategy of offering the patient the option to plan a medical consultation with the GP (OR 0.57; 95\% CI 
Table 2 Characteristics of respondents $(n=377)$

$$
\%
$$

$\mathbf{N}$

$\%$

$\mathbf{N}$

\begin{tabular}{|c|c|c|c|c|c|}
\hline Gender parent & & & Area & & \\
\hline Female & 86.7 & 327 & Rural area & 40.6 & 153 \\
\hline \multirow[t]{2}{*}{ Male } & 13.3 & 50 & Suburban area & 17.0 & 64 \\
\hline & & & Urban area & 42.5 & 160 \\
\hline \multicolumn{6}{|l|}{ Age parent } \\
\hline $17-22$ & 2.1 & 8 & Number of children & & \\
\hline $23-27$ & 13.5 & 51 & 1 & 30.0 & 113 \\
\hline $28-32$ & 30.8 & 116 & 2 & 45.4 & 171 \\
\hline $33-37$ & 30.5 & 115 & 3 & 16.4 & 62 \\
\hline $38-42$ & 17.0 & 64 & 4 & 4.8 & 18 \\
\hline $43-48$ & 4.8 & 18 & $\geq 5$ & 3.0 & 13 \\
\hline Missing & 1.3 & 5 & $($ Mean=2.1) & & \\
\hline Education & & & Age of youngest $c$ & & \\
\hline No education & 0.5 & 2 & 0 & 14.6 & 55 \\
\hline Primary school & 2.4 & 9 & 1 & 15.1 & 57 \\
\hline Lower secondary education & 11.7 & 44 & 2 & 21.8 & 82 \\
\hline Intermediate vocational education & 41.6 & 157 & 3 & 13.5 & 51 \\
\hline Higher secondary education & 8.0 & 30 & 4 & 4.2 & 16 \\
\hline Higher vocational education & 25.2 & 95 & Missing & 30.8 & 116 \\
\hline University degree & 9.3 & 35 & $($ Mean=1.7) & & \\
\hline \multirow[t]{2}{*}{ Missing } & 1.3 & 5 & & & \\
\hline & & & Age of oldest chilc & & \\
\hline Family income & & & $0-4$ & 52.8 & 199 \\
\hline$>€ 56800$ & 34.2 & 129 & $5-9$ & 38.2 & 144 \\
\hline About $€ 56800$ & 34.5 & 130 & $10-14$ & 7.2 & 27 \\
\hline$<€ 56800$ & 27.6 & 104 & $15-21$ & 1.9 & 7 \\
\hline Missing & 3.7 & 14 & $($ Mean=4.8) & & \\
\hline
\end{tabular}

0.34 to 0.97$)$. Furthermore, parents with more than regularly chose an underdemand solution (OR 0.95 ; one child more frequently chose an underdemand solution for a high-urgent condition (OR 2.04; $95 \%$ CI 0.92 to 0.98$)$.

Table 3 Underdemand and overdemand for case scenarios at baseline $(n=371)$

\begin{tabular}{llllllc}
\hline & \multicolumn{2}{c}{ Overdemand chosen } & \multicolumn{2}{c}{$\begin{array}{l}\text { Medically appropriate demand } \\
\text { chosen }\end{array}$} & \multicolumn{2}{c}{ Underdemand chosen } \\
\cline { 2 - 7 } Scenario & $\%$ & $\mathbf{N}$ & $\%$ & $\mathbf{N}$ & $\%$ & $\mathbf{N}$ \\
\hline Total non-urgent scenarios & 41.7 & 90 & 58.3 & 126 & 0.0 & 0 \\
Swallow marble & 78.2 & 79 & 21.8 & 22 & 0.0 & 0 \\
Earache & 9.6 & 11 & 90.4 & 104 & 0.0 & 0 \\
Total urgent scenarios & 3.9 & 6 & 50.3 & 78 & 45.8 & 71 \\
Fever & 1.2 & 1 & 79.0 & 64 & 19.8 & 16 \\
Diarrhoea & 6.8 & 5 & 18.9 & 14 & 74.3 & 55 \\
\hline
\end{tabular}


Table 4 Overdemand and underdemand for each demand management strategy (\%)

\begin{tabular}{clclc} 
& & & \multicolumn{2}{l}{ Underdemand for urgent case } \\
& Overdemand for non-urgent case scenarios $(\mathbf{n}=609)$ & scenarios (n=752) \\
\hline & $\%$ & $\mathbf{N}$ & $\%$ & $\mathbf{N}$ \\
\hline Baseline strategy & 41.7 & 90 & 50.3 & 78 \\
Online advice & 11.3 & 8 & 16.5 & 15 \\
Copayment & 31.7 & 39 & 50.0 & 88 \\
GP consult planned & 44.4 & 48 & 41.0 & 50 \\
Overview medical cost & 35.2 & 32 & 39.4 \\
\hline
\end{tabular}

GP, general practitioner.

\section{DISCUSSION AND CONCLUSION Discussion}

The findings of this study imply that decisions on healthcare seeking by parents of young children can be influenced. For both non-urgent and urgent case scenarios, about half of the parents did not chose the most medically appropriate decision. Demand management strategies have the potential to help patients make medically appropriate decisions. The strategy 'online advice' seems to have the highest potential to positively influence patient demand as it influenced decisions in both urgent and non-urgent cases. The use of this strategy has both the potential of reducing medically unnecessary use of the GPC and could also enhance safety in healthcare, as patients are more likely to contact a doctor in urgent cases. Comparable results have been found in studies on the management of chronic diseases such as depression and lower back pain. ${ }^{12-14}$ In the questionnaire a relatively customised advice (applicable to the specific condition) was presented, and it was mentioned that the advice was given by an online application certified by the Dutch Society of General Practitioners (NHG). This set-up of posting a 'certified' and customised advice might have had a positive influence on the patients' willingness to follow it. This is also mentioned by parents in a British study about information needs of parents for acute childhood illness. ${ }^{15}$ In addition, the capabilities of the person receiving the advice also influence the way a person acts on it.

Even though 9 in 10 inhabitants in the Netherlands access the internet every day, it is still debatable whether all would actually use an online application if they would be worried or panicking about their (child's) condition. Also, it is essential to remain vigilant to how access limitations might exclude certain groups of society from accessing such information. A recent study shows that people who are older, have a higher income or live in rural areas are less likely to use mobile health applications. ${ }^{16}$ On the other hand, access to internet on smartphones or notebooks is also high in socially deprived populations.

We also found that implementing copayment or giving an overview of the medical cost did not affect patient decision-making for non-urgent scenarios. In addition, for the urgent case scenarios there was no influence from implementing copayment, which would imply that it does not affect patient safety. Other studies

Table 5 Logistic regression for overdemand and underdemand $\dagger$

\section{Overdemand for non-urgent case scenarios Underdemand for urgent case} $(n=591)$

\begin{tabular}{|c|c|c|c|c|}
\hline Variables & OR & $95 \% \mathrm{Cl}$ & OR & $95 \% \mathrm{Cl}$ \\
\hline Strategy: copayment & 0.62 & 0.38 to 1.03 & 0.84 & 0.53 to 1.33 \\
\hline Strategy: overview medical cost & 0.97 & 0.56 to 1.70 & 0.59 & 0.38 to $0.92^{*}$ \\
\hline Gender parent: male & 0.91 & 0.52 to 1.57 & 0.69 & 0.42 to 1.15 \\
\hline$>1$ Child & 0.64 & 0.43 to $0.96^{*}$ & 2.04 & 1.39 to $2.98^{*}$ \\
\hline Highly educated & 1.07 & 0.71 to 1.63 & 0.93 & 0.64 to 1.35 \\
\hline High income & 1.07 & 0.71 to 1.63 & 0.94 & 0.65 to 1.37 \\
\hline
\end{tabular}

${ }^{*} p<0.05$, in bold.

†GP practice was added to account for clustering of patients within GP practices.

GP, general practitioner. 
also found that copayment was not an important driver for patient decision-making, ${ }^{17} 18$ but other studies found some effects of copayment. A study at the emergency department showed a reduction in demand from patients with non-urgent conditions. ${ }^{19}$ In line with this outcome, some argue that copayment stimulates patients to consider whether they really need healthcare at that moment. This would eventually contribute to lowering collective healthcare costs. ${ }^{20}$ On the other hand, critics argue that the fee could deter patients with serious illnesses from visiting the emergency department ${ }^{21}$ and could lead to greater inequity, especially for socially deprived patients. ${ }^{22} 23$

While we expected the 'GP consult planned' demand management strategy to affect the non-urgent cases, it only appeared to affect patient decision-making positively in relation to urgent conditions. Seemingly those seeking help for a non-urgent problem are not easily influenced by an organisational strategy.

Regarding patient characteristics, we found that patients with more children seem to make more underdemand healthcare choices, resulting in less overdemand. A possible explanation is that these parents, due to experience, are less prone to panic. Interestingly, they seem more likely to underestimate medical urgencies. Also, the probability that parents will choose an underdemand solution increases when a parent is older; we could philosophise that older parents are more able to assess a healthcare problem.

\section{Strengths and weaknesses and recommendations for further research}

The selected sample is diverse in terms of residential zones, income, education, age and number of children. These characteristics reflect the Dutch population. ${ }^{24} \mathrm{We}$ chose to use written case scenarios. A drawback of this design is that respondents were confronted with hypothetical situations; consequently, emotional reactions or actual financial payments that occur in real-life situations are not completely reflected in this research. Besides, it is possible that the respondents were eager to answer 'correctly', especially for the cases in which the strategy online advice was incorporated as they were provided with information about the appropriate response. This may have inflated the effect of this strategy. On the other hand, the information scenario was closer to reality (responders actually received it), which has enhanced the impact of this strategy. Prospective evaluation studies of demand management strategies, ideally designed as randomised trials, are required to examine their impact.

We used two non-urgent and two urgent case scenarios to test the demand management strategies. Although the cases were validated by an expert panel and they had consensus about the appropriate choice, we saw great differences in answers between the two urgent cases. We noticed that many parents chose an underdemand solution for one of the urgent cases (child with fever). In hindsight, as we did not expect such a high percentage of parents to make an underdemand choice for the urgent case scenarios (especially for the child with fever case), this case may not have been the best scenario to test the demand management strategies. Further research using more, alternate case scenarios is needed to confirm the results of this study.

There might be a relation to the amount of the copayment and its effectiveness. ${ }^{4}$ In this research we only tested one amount for the GPC, but if policymakers would want a more conclusive assessment of this strategy, different amounts should be tested. Finally, although the described strategies were merely effective under either urgent or non-urgent conditions, it would be interesting to research the effects of implementing strategies simultaneously. For example, combining online advice and online overview of medical cost could possibly increase the effectiveness of the strategies.

\section{Conclusion}

We conclude that there are demand management strategies that can influence a patient's ability to make medically appropriate healthcare choices for urgent and non-urgent conditions during out-of-hours. Guiding and advising patients online appears to have high potential, as it influences patient decision-making positively in both urgent and non-urgent conditions. Advising patients on what decision to take when a health condition occurs offers the patients a level of certainty that can positively influence their decision-making. Further research with more case scenarios is needed to confirm the results of this study. It is also necessary to study the impact of this strategy on patient safety in practice.

\section{Practice implications}

Our study can have broad implications in a world where more people use the internet and policymakers are struggling to limit healthcare costs while maintaining high quality and safety in healthcare. This research shows the great potential of online health applications and we believe that an independent, certified and customised tool, such as thuisarts.nl, ${ }^{25}$ should be promoted. It may lead to a reduction in the use of GPCs for non-urgent complaints that could wait until the next day and to safer use for patients with urgent complaints.

Correction notice This paper has been amended since it was published Online First. Owing to a scripting error, some of the publisher names in the references were replaced with 'BMJ Publishing Group'. This only affected the full text version, not the PDF. We have since corrected these errors and the correct publishers have been inserted into the references.

Acknowledgements We would like to thank all the GP practices who participated in this research.

Contributors MJG designed the study, gathered the data, participated in performing the statistical analyses, interpreted the data and drafted the manuscript. EK designed the study, participated in performing the statistical analyses, interpreted the data and drafted the manuscript. JP helped to gather data, participated in the interpretation of the data and drafted the manuscript. JK designed the study, performed the statistical analyses and revised the manuscript critically. MW participated in the interpretation of the data and revised the manuscript critically for important intellectual content. PG designed the study, 
participated in the interpretation of the data and revised the manuscript critically. All authors read and approved the final manuscript.

Funding This research did not receive any specific grant from funding agencies in the public, commercial or not-for-profit sectors.

Competing interests All authors have completed the ICMJE uniform disclosure form atwww.icmje.org/coi_disclosure.pdf and declare no support from any organisation for the submitted work; no financial relationships with any organisations that might have an interest in the submitted work in the previous 3 years; and no other relationships or activities that could appear to have influenced the submitted work.

Ethics approval The research ethics committee of the Radboud University Medical Center (CMO Arnhem-Nijmegen) was consulted and concluded that the study does not fall within the remit of the Medical Research Involving Human Subjects Act (WMO) (file number: 2016/2870).

Provenance and peer review Not commissioned; externally peer reviewed.

Data sharing statement The data set will be available on request.

Open Access This is an Open Access article distributed in accordance with the Creative Commons Attribution Non Commercial (CC BY-NC 4.0) license, which permits others to distribute, remix, adapt, build upon this work non-commercially, and license their derivative works on different terms, provided the original work is properly cited and the use is non-commercial. See: http://creativecommons.org/ licenses/by-nc/4.0/

(c) Article author(s) (or their employer(s) unless otherwise stated in the text of the article) 2017. All rights reserved. No commercial use is permitted unless otherwise expressly granted.

\section{REFERENCES}

1. Giesen P, Smits M, Huibers L, et al. Quality of after-hours primary care in the Netherlands: a narrative review. Ann Intern Med 2011;155:108-13.

2. Ineen Benchmarkbulletin huisartsenposten 2014: (Benchmark report GP cooperatives 2014), 2015.

3. Smits M, Keizer E, Huibers L, et al. GPs' experiences with out-ofhours GP cooperatives: a survey study from the Netherlands. Eur $J$ Gen Pract 2014;20:196-201.

4. Keizer E, Maassen I, Smits M, et al. Reducing the use of out-of-hours primary care services: a survey among dutch general practitioners. Eur J Gen Pract 2016;22:189-95.

5. Vickery DM, Lynch WD. Demand management: enabling patients to use medical care appropriately. J Occup Environ Med 1995;37:551-7.

6. Bryant CD, management D. And case management: a conservation strategy. Prof Case Manag 2007;12:272-802.

7. Giesen P, Hammink A, Mulders A, et al. Te snel naar de huisartsenpost (Too easy to go to the GP cooperative). Medisch contact 2009;06:239-42.

8. de Bont EG, Lepot JM, Hendrix DA, et al. Workload and management of childhood fever at general practice out-of-hours care: an observational cohort study. BMJ Open 2015;5:e007365.
9. Smits M, Peters Y, Broers S, et al. Association between general practice characteristics and use of out-of-hours GP cooperatives. BMC Fam Pract 2015;16:52.

10. Smits M, Hanssen S, Huibers L, et al. Telephone triage in general practices: a written case scenario study in the Netherlands. Scand J Prim Health Care 2016;34:28-36.

11. Centraal Bureau voor de Statistiek (Statistics Netherlands) Gemiddeld inkomen; particuliere huishoudens naar diverse kenmerken (Average income; private households to various characteristics). http://statline.cbs.nl/Statweb/publication/?DM= SLNL\&PA $=70843 N E D \& D 1=4 \& D 2=0 \& D 3=0-4 \& D 4=11-14 \& V W=T$ (Accessed 26 Sep 2016).

12. Andersson G, Cuijpers P. Internet-based and other computerized psychological treatments for adult depression: a meta-analysis. Cogn Behav Ther 2009;38:196-205.

13. Berger T, Hämmerli K, Gubser N, et al. Internet-based treatment of depression: a randomized controlled trial comparing guided with unguided self-help. Cogn Behav Ther 2011;40:251-66.

14. Buhrman M, Fältenhag S, Ström L, et al. Controlled trial of Internetbased treatment with telephone support for chronic back pain. Pain 2004;111:368-77.

15. Jones $\mathrm{CH}$, Neill S, Lakhanpaul M, et al. Information needs of parents for acute childhood illness: determining 'what, how, where and when of safety netting using a qualitative exploration with parents and clinicians. BMJ Open 2014;4:e003874.

16. Bhuyan SS, Lu N, Chandak A, et al. Use of Mobile Health applications for Health-Seeking Behavior among US adults. J Med Syst 2016;40:153.

17. de Valk J, Taal EM, Nijhoff MS, et al. Self-referred patients at the Emergency Department: patient characteristics, motivations, and willingness to make a copayment. Int J Emerg Med 2014;7.

18. Philips H, Remmen R, De Paepe P, et al. Use of out-of-hours services: the patient's point of view on co-payment a mixed methods approach. Acta Clin Belg 2013;68:1-8.

19. Reitsma-van Rooijen M, Jong de J. Betalen voor de SEH schrikt af (Paying for the emergency department scares). Medisch contact 2010;65:1479-81.

20. Robinson R. User charges for health care. In: Mossialos E, Dixon A, Figueras J, eds. Critical challenges for health care reform in Europe. Open university press, Buckingham, 2002.

21. Hsu J, Price M, Brand R, et al. Cost-sharing for emergency care and unfavorable clinical events: findings from the safety and financial ramifications of ED copayments study. Health Serv Res 2006;41:1801-20.

22. Lostao L, Regidor E, Geyer S, et al. Patient cost sharing and social inequalities in access to health care in three western European countries. Soc Sci Med 2007;65:367-76.

23. Kelaher M, Dunt D, Day S, et al. Effects of financial disadvantage on use and non-use of after hours care in Australia. Health Policy 2006;79:16-23.

24 Centraal Bureau voor de Statistiek (Statistics Netherlands). Trends in Nederland, 2015 (Trends in the Netherlands, 2015). http://download. cbs.nl/pdf/trends-in-nederland-2015-web.pdf (Accessed 26 Sep 2016).

25 Drenthen T, Beijaert RP, Jansen PW, et al. Thuisarts.nl, hoe bevalt dat? ervaringen na 3 jaar Thuisarts.nl [What do you think of Thuisarts.nl? experiences after 3 years of www.thuisarts.nl]. Ned Tijdschr Geneeskd 2014;158:A8282. 
Correction: The impact of demand management strategies on parents' decision-making for out-of-hours primary care: Findings from a survey in the Netherlands

Giesen M, Keizer E, van de Pol J, et al. The impact of demand management strategies on parents' decision-making for out-of-hours primary care: findings from a survey in The Netherlands. BMJ Open 2017;7:e014605. doi: 10.1136/bmjopen-2016-014605

The article has been corrected since it first published. 'CI' has been changed to ' $95 \%$ CI' several times throughout the paper and reference 24 has been added.

Open Access This is an Open Access article distributed in accordance with the terms of the Creative Commons Attribution (CC BY 4.0) license, which permits others to distribute, remix, adapt and build upon this work, for commercial use, provided the original work is properly cited. See: http://creativecommons.org/licenses/by/4.0/

C Article author(s) (or their employer(s) unless otherwise stated in the text of the article) 2017. All rights reserved. No commercial use is permitted unless otherwise expressly granted.

BMJ Open 2017;7:e014605corr1. doi:10.1136/bmjopen-2016-014605corr1

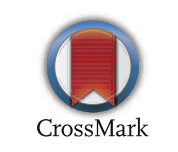

